\title{
Perhitungan laju korosi dan perancangan sistem proteksi katodik anoda korban di lambung kapal tugboat Bontang 04 PT Badak NGL Bontang
}

\section{R. A. Saputra*, P. D. Setyawan, S. Sugiman, A. Zainuri}

Teknik Mesin Fakultas Teknik Universitas Mataram, Jln. Majapahit No. 62 Mataram Nusa Tenggara Barat Kode Pos : 83125, Telp. (0370) 636087; 636126; ext 128 Fax (0370) 636087.

*Email: novaardi082@gmail.com

\section{ARTICLE INFO}

Article History:

Received February 2017

Accepted October 2017

Available online 30 December 2017

Keywords:

Corrosion rate

Cathode protection

Sacrificial anodes

Ultrasonic test

Ship hull

In cooperation with SNMI XI 2017

Special Edition
ABSTRACT

Corrosion happens differently for each point of hull plate which caused of corrosion rate differences. So that is very important to measure it for each point, which is calculated using Weight Gain Loss Method. The measurement of plate thickness that used is Ultrasonic Test Method conducted by PT BKI. To determine the condition of ship protection, then the coating and sacrificial anode system is evaluated by testing the composition and current and voltage of anode as well. Furthermore, the number and position of anode is also analyzed. So that the re-design of cathode protection is needed by referring to the PT $B K l$ 's standards. Then the prediction of corrosion rate is calculated by using the design of cathode protection. The largest corrosion rates are in the amidships and portside for each plate lane, they are on the keel plate point $K 3$ is $0.37 \mathrm{~mm} /$ years, pedestal plate point $\mathrm{A} 4$ is $1.05 \mathrm{~mm} /$ years, bilge plate point B4 is $0.62 \mathrm{~mm} /$ years and side plate point C5 is $0.39 \mathrm{~mm} /$ years. But the number of installed anode is 31 anodes with an irregular position. So in this study, done the redesign system of cathode protection based on regulations issued by PT BKI, with the result of the number of the anode is 56 units. Using the design, then carried a prediction by the result is lower, that on the keel plate is $0.073 \mathrm{~mm} /$ years, pedestal plate is $0.021 \mathrm{~mm} /$ years, bilge plate is $0.013 \mathrm{~mm} / y$ ears and the side plate is $0.014 \mathrm{~mm} /$ years.

\section{PENDAHULUAN}

Sunarto (2011) menganalisa hasil pengukuran korosi struktur kapal ikan minajaya menggunakan ultrasonic test. Dalam menghitung laju korosi yang terjadi pada lambung kapal dilakukan dengan menggunakan metode Weight Gain Loss (WGL). Hasil dari penelitian ini diketahui bahwa tingkat laju korosi komponen kapal minajaya selama 15 tahun beroperasi adalah berkisar antara 0.002-0.1 mm/tahun pada

https://doi.org/10.29303/dtm.v7i2.158 
daerah lambung setinggi maindeck dan 0.04-0.3 $\mathrm{mm} /$ tahun pada daerah deck struktur. Persentase keausan pada lajur-lajur pelat lambung kapal minajaya kurang lebih sebesar $5 \%$ dan pada daerah deck struktur adalah lebih kurang sebesar $13.8 \%$, sehingga dapat dikatakan bahwa kapal masih layak untuk digunakan. Dari penelitian ini diketahui jenis korosi yang terjadi adalah korosi merata $91 \%$ dan korosi sumuran sebesar $9 \%$.

\section{METODE PENELITIAN}

Penelitian ini dilakukan di Galangan Kapal Pantai Marina, PT Badak NGL Bontang, Kalimantan Timur pada Januari hingga Februari 2017. Objek penelitian ini adalah lambung kapal Tugboat Bontang 04 PT Badak NGL, yaitu pelat lunas $(K)$, pelat alas $(A)$, pelat bilga $(B)$, dan pelat sisi $(\mathrm{C})$.

Material lambung kapal Tugboat Bontang 04 adalah Carbon Steel SS400. Dengan dimensi utama kapal yaitu Length Over A/l ( $\mathrm{L}_{\mathrm{OA}}=37.60$ $\mathrm{m})$, Length Between Perpendiculars $\left(\mathrm{L}_{\mathrm{BP}}=32.90\right.$ $\mathrm{m})$, Breath $(\mathrm{b}=10.00 \mathrm{~m})$, Depth $(\mathrm{H}=4.50 \mathrm{~m})$ dan $\operatorname{Draft}(\mathrm{D}=3.50 \mathrm{~m})$.

Melalui pengujian lansung menggunakan elektroda $\mathrm{Ag} / \mathrm{AgCl}$ pada media air laut, diperoleh nilai current output anoda $(0.23$ A) dengan tegangan (-0.86 V). Spesifikasi anoda korban yang digunakan di lambung Tugboat Bontang 04 adalah paduan seng $(\mathrm{Zn})$ dengan tipe Wilson Walton Z100 dengan berat netto (4.2-5 $\mathrm{kg} /$ anoda).

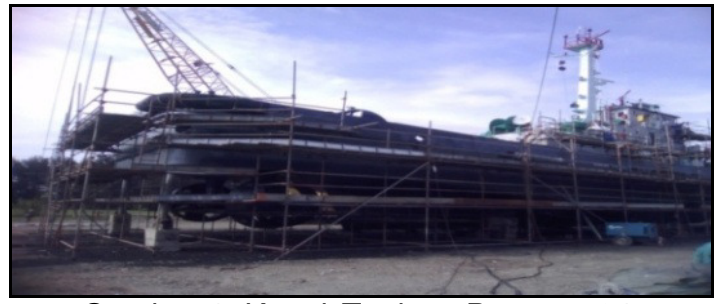

Gambar 1. Kapal Tugboat Bontang 04.

Instrumen ukur yang digunakan dalam penelitian ini adalah alat ultrasonic test tipe Dakota MVX.

\section{Langkah-langkah Penelitian}

a. Menghitung Laju Korosi

Pada penelitian ini, pengukuran tebal pelat dilakukan dengan metode ultrasonic test oleh pihak PT BKI. Alat ultrasonic test yang digunakan adalah tipe Dakota MVX, seperti pada Gambar 2.

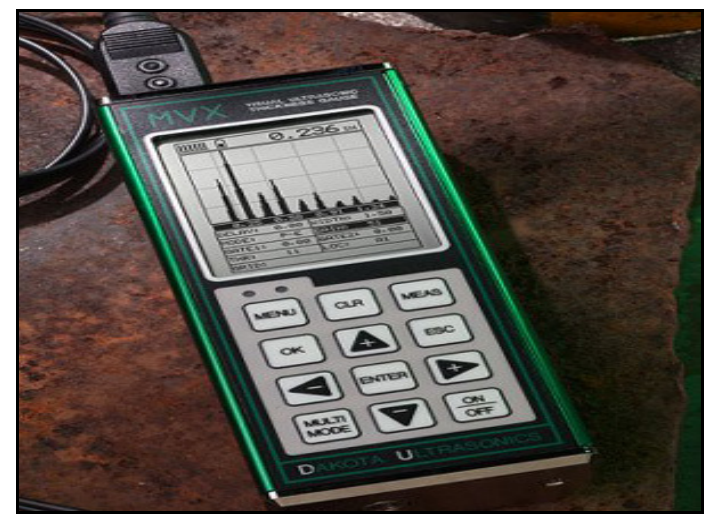

Gambar 2. Alat ukur tebal pelat (ultrasonic test).

Ketebalan hasil ultrasonic test dihitung berdasarkan rata-rata tebal pada masing-masing titik pelat. Dalam menghitung laju korosi menggunakan Metode weight gain loss didasarkan pada selisih berat (W) yang diperoleh antara berat pelat lambung kapal tahun 2013 dan setelah beroperasi pada tahun 2016. Berat pelat dihitungan dengan Persamaan (1) dan laju korosi dihitung pada masing-masing titik pelat lambung kapal dengan persamaan (2), Trethewey and Camberlain (1991).

$W-A \times t \times$ donsitas baja

$C_{R}=\frac{5,76 \times W}{\rho \times A_{l} \times T_{g}}$

b. Mengevaluasi Sistem Proteksi Kapal

Jenis proteksi yang digunakan lambung kapal adalah sistem coating dan anoda korban. Sistem coating kapal dapat dievaluasi melalui painting report sesuai standar yang diaplikasikan. Sedangkan pada anoda korban dilakukan pengujian komposisi dan arus tegangan proteksi, dengan alat berturut-turut seperti pada Gambar 3 dan 4.

c. Merancang Sistem Anoda Korban

Dalam merancang anoda korban mengarah pada standar PT BKI (Guidance For The Corrosion Protection and Coating Systems tahun 2004 dan Rules For Hulls tahun 2014). Perhitungan yang dilakukan dalam mendesain anoda korban adalah kebutuhan arus proteksi (Ic), kebutuhan berat anoda (M), jumlah kebutuhan anoda $(\mathrm{N})$, jarak dan posisi anoda. Dalam menentukan posisi dan jarak digunakan panjag kapal yang terendam untuk mendapatkan jarak merata antar anoda. Dalam merancang sistem anoda korban digunakan densitas arus ( $\left.\mathrm{i}_{\mathrm{c}}\right)$ adalah $0,02 \mathrm{~A} / \mathrm{m}^{2}$, Trethewey and Camberlain (1991). 


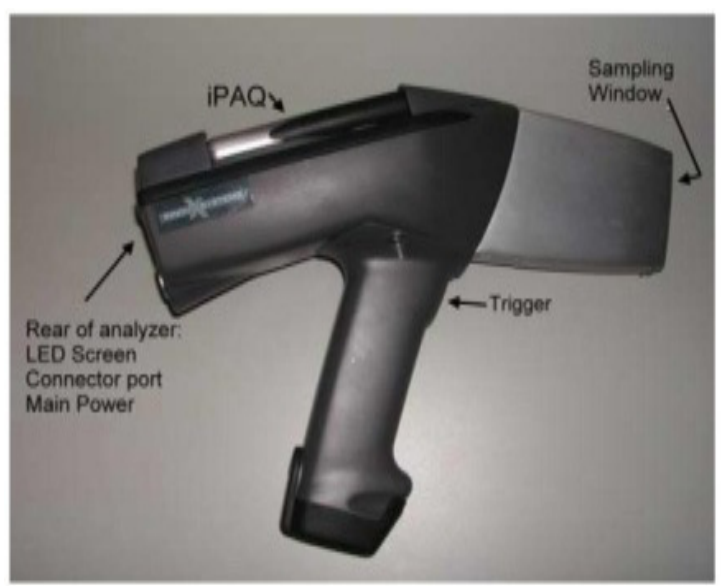

Analyzer, with iPAQ attached.

Gambar 3. Analyzer InnovXsystem.

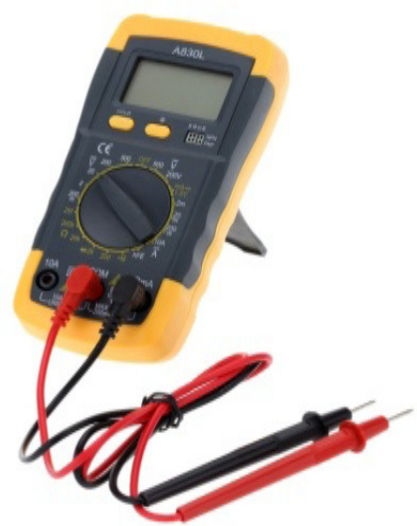

Gambar 4. Multimeter

d. Memprediksi Nilai Laju Korosi

Dengan menggunakan densitas arus hasil rancangan, prediksi nilai laju korosi dapat diperoleh yang didasarkan pada Hukum Faraday sesuai persamaan (3), Fontana (1986):

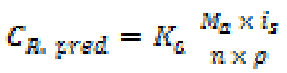

\section{HASIL DAN PEMBAHASAN}

Dengan menggunakan persamaan (1) dan (2), diperoleh nilai laju korosi pelat lambung kapal setelah beroperasi dari tahun 2013 hingga
2016 yang dapat dilihat pada Gambar 5, 6, 7, dan 8.

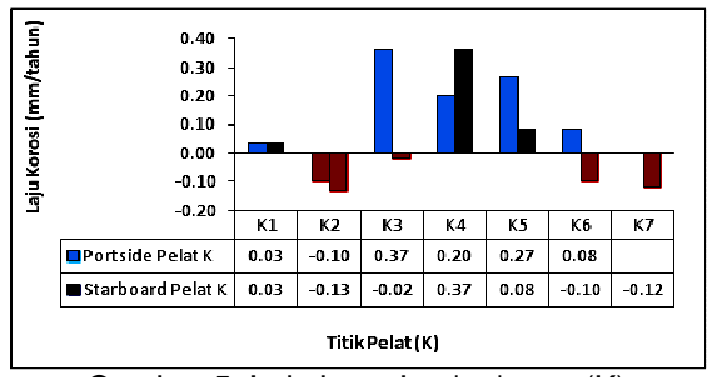

Gambar 5. Laju korosi pelat lunas (K)

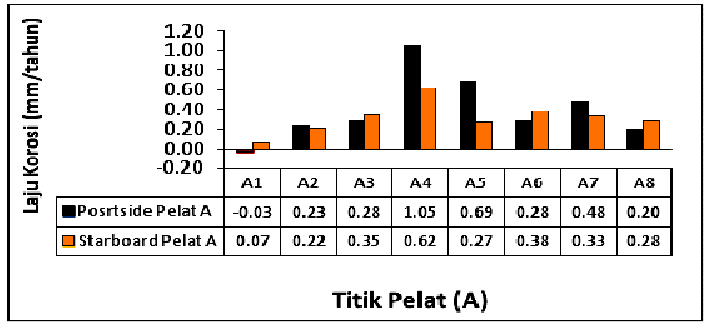

Gambar 6. Laju korosi pelat alas (A).

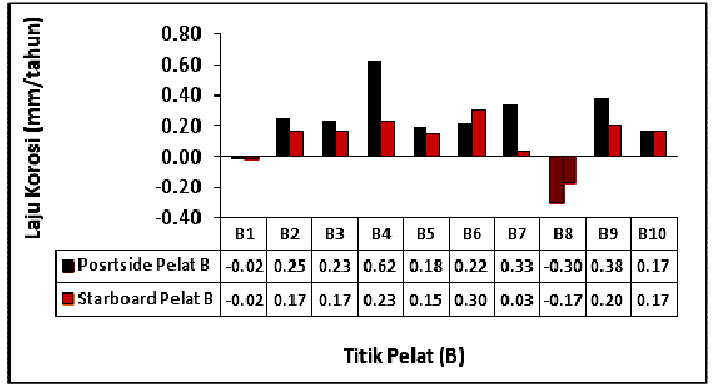

Gambar 7. Laju korosi pelat bilga (B).

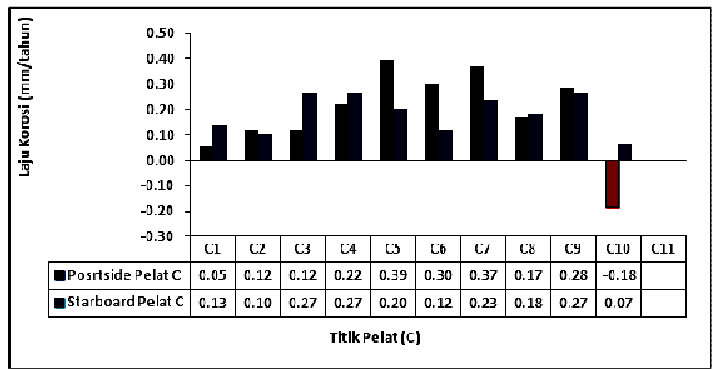

Gambar 8. Laju korosi pelat sisi (C). 


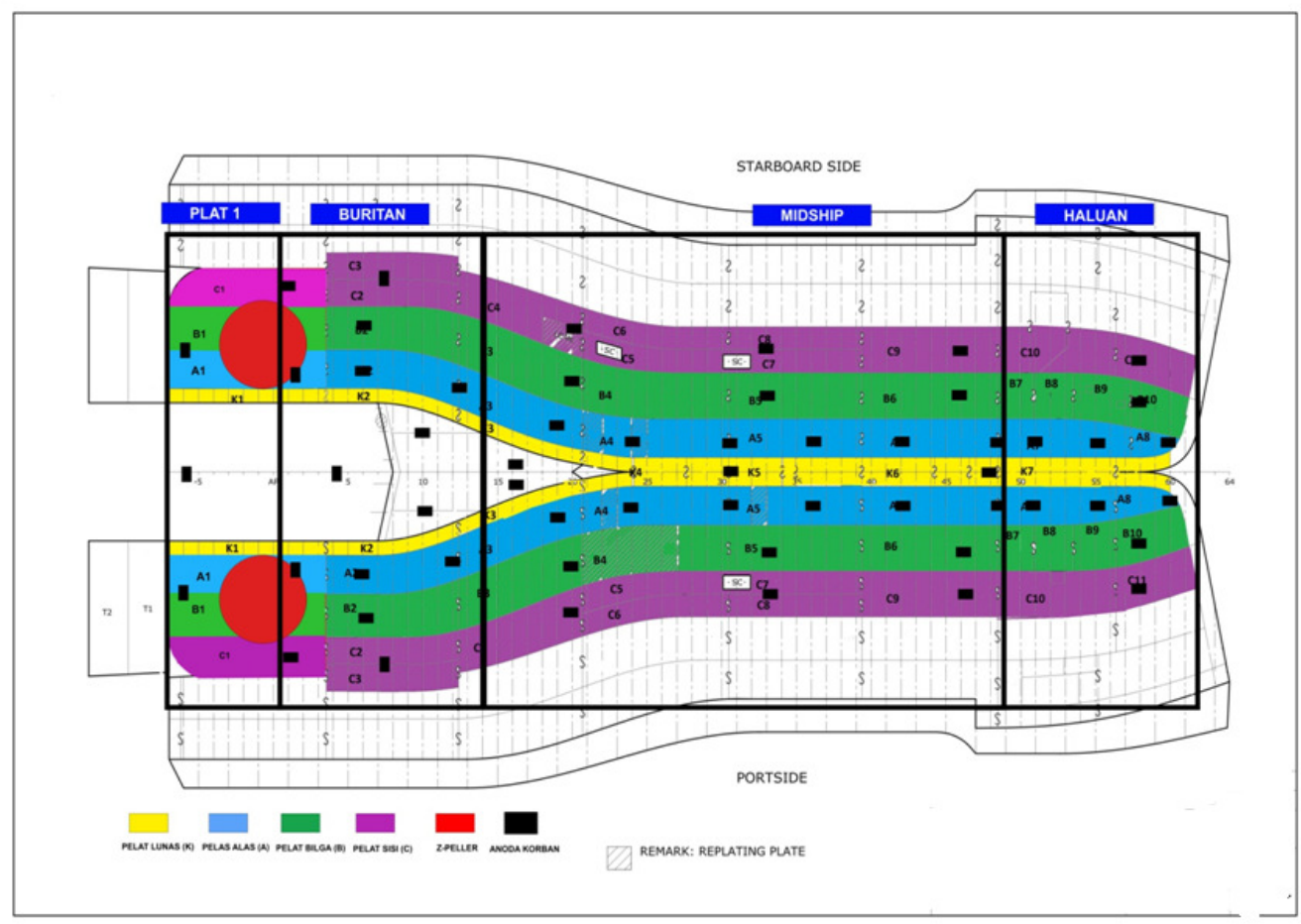

Gambar 9. Hasil rancangan sistem anoda korban.

Tabel 1. Prediksi nilai laju korosi

\begin{tabular}{|c|c|c|c|c|c|c|c|c|}
\hline Lajur pelat & $\begin{array}{l}\text { Luas } \\
\text { Pelat } \\
\left(\mathrm{m}^{2}\right)\end{array}$ & $\begin{array}{l}\text { Jumlah } \\
\text { anoda } \\
\text { (buah) }\end{array}$ & $\begin{array}{c}\text { Luas } \\
\text { lingkup } \\
\text { anoda } \\
\mathrm{Aa} \\
\left(\mathrm{m}^{2}\right)\end{array}$ & $\begin{array}{l}\text { Is } \\
\text { (A) }\end{array}$ & $\begin{array}{l}\text { lc } \\
\text { (A) }\end{array}$ & $\begin{aligned} & i s=(l s-l c) /_{A_{G}} \\
&\left(\mathrm{~A} / \mathrm{m}^{2}\right)\end{aligned}$ & $\begin{array}{l}\text { CR. Pred. } \\
\text { (mm/th) }\end{array}$ & $\begin{array}{c}\mathrm{C}_{\mathrm{R}} \\
(\mathrm{mm} / \mathrm{th})\end{array}$ \\
\hline Pelat Lunas (K) & 9.53 & 3 & 3.18 & 0.23 & 0.03 & 0.063 & 0.073 & 0.18 \\
\hline Portside Alas (A) & 72.71 & 12 & 6.06 & 0.23 & 0.123 & 0.018 & 0.021 & 0.46 \\
\hline Starboard Alas (A) & 72.71 & 12 & 6.06 & 0.23 & 0.123 & 0.018 & 0.021 & 0.32 \\
\hline Portside Bilga (B) & 37.97 & 5 & 7.59 & 0.23 & 0.152 & 0.011 & 0.013 & 0.30 \\
\hline $\begin{array}{c}\text { Starboard Bilga } \\
\text { (B) }\end{array}$ & 37.97 & 5 & 7.59 & 0.23 & 0.152 & 0.011 & 0.013 & 0.18 \\
\hline Portside Sisi (C) & 36.63 & 6 & 6.10 & 0.23 & 0.146 & 0.012 & 0.014 & 0.22 \\
\hline Starboard Sisi (C) & 36.63 & 6 & 6.10 & 0.23 & 0.146 & 0.012 & 0.014 & 0.18 \\
\hline
\end{tabular}

Dari Gambar 5, 6, 7, dan 8, terlihat bahwa laju korosi tertinggi selalu terjadi pada bagian posrtside (kiri) dan bagian midship (tengah) lambung kapal. Hal ini terjadi karena kapal tugboat selalu bersandar dengan posisi sebelah kiri kapal berdekatan dengan tembok pelabuhan sehingga konsentrasi biofouling lebih tinggi pada bagian kiri kapal. Sedangkan bagian tengah kapal adalah bagian yang paling menjorok ke dalam (paling bawah), sehingga proteksinya lebih rentan rusak dan menyebabkan konsentrasi biofouling juga kan tinggi. Dengan keadaan tersebut akan terjadi laju korosi yang lebih tinggi dari pada bagian yang lain. Nilai prediksi laju korosi ditunjukkan pada Tabel 1

Berdasarkan Painting Report tahun 2017, maka diketahui bahwa sistem coating yang terapkan sudah sesuai standar perusahaan Spesifikasi No. 33. Untuk anoda korban, hasil uji komposisi menunjukkan kandungan unsur $\mathrm{Zn}$ mencapai $86,81 \%$. Sedangkan untuk uji arus menghasilkan $0.23 \mathrm{~A}$ dan uji tegangan menghasilkan $-0.86 \mathrm{~V}$. 
Hasil rancangan menunjukkan besarnya kebutuhan arus proteksi lambung kapal (IC) adalah 6,41 A, kebutuhan berat anoda (M) adalah $227.09 \mathrm{~kg}$, jumlah anoda (N) adalah 56 buah dengan anode arrangement seperti pada Gambar 9.

\section{KESIMPULAN}

Dari hasil yang diperoleh dalam penelitian ini, maka dapat ditarik beberapa kesimpulan, antara lain:

a. Laju korosi tertinggi terjadi pada bagian tengah kapal (midship) dan bagian portside (kiri) lambung kapal, yaitu pada pelat lunas (K) titik K3 (0.37 mm/th), pelat alas $(A)$ titik A4 (1.05 mm/th), pelat bilga (B) titik B4 (0.62 $\mathrm{mm} / \mathrm{th})$ dan pelat sisi (C) titik C5 (0.39 $\mathrm{mm} / \mathrm{th})$.

b. Terdapat kelemahan pada sistem proteksi yang diaplikasikan, yaitu kurangnya jumlah anoda korban yang dipasang dan jarak antar anoda korban yang tidak jelas.

c. Rancangan sistem anoda korban yang baru menghasilkan jumlah kebutuhan arus proteksi (IC) adalah $6.41 \mathrm{~A}$, jumlah anoda korban minimal 53 buah dengan arus proteksi per anoda adalah $0.23 \mathrm{~A}$, rancangan posisi dan jarak antar anoda seperti pada Lampiran 5.

Prediksi nilai laju korosi berdasarkan hasil rancangan sistem proteksi anoda korban yang baru adalah pada pelat lunas $(\mathrm{K})$ adalah 0.073 $\mathrm{mm} / \mathrm{th}$, pelat alas $(\mathrm{A})$ adalah $0.021 \mathrm{~mm} / \mathrm{th}$, pelat bilga (B) adalah $0.013 \mathrm{~mm} /$ th dan pelat sisi $(\mathrm{C})$ adalah $0.014 \mathrm{~mm} / \mathrm{th}$.

\section{UCAPAN TERIMA KASIH}

Pada kesempatan ini penulis menyampaikan banyak terima kasih kepada semua pihak yang telah banyak membantu dalam pelaksanaan penelitian ini, baik berupa moril maupun materil. Penulis juga mengucapkan terima kasih kepada PT Badak NGL yang telah memberikan kesempatan untuk belajar dan melakukan penelitian di perusahaan. Selain itu penulis juga mengucapkan terima kasih kepada Jurusan Teknik Mesin, Universitas Mataram.

\section{DAFTAR PUSTAKA}

Fontana M.G., 1986, Corrosion engineering, 3th Edition, Mc Graw Hill Book Co., New York.

PT Biro Klasifikasi Indonesia, 2014, Rules for hulls, BKI. Jakarta.

Sunarto, 2011, Analisa hasil pengukuran korosi struktur ikan minajaya menggunakan ultrasonic test, Universitas Hasanuddin. Makassar.

Trethewey K.R., Chamberlain J., 1991, Korosi untuk mahasiswa sains dan rekayasa, PT. Gramedia Pustaka Utama, Jakarta. 